\title{
Semiotic Analysis of the Myth of Eroticism in English Song Lyrics
}

\author{
Reski Ramadhani, Susi Yuliawati, Dadang Suganda
}

Department of Linguistics, Faculty of Cultural Sciences, Universitas Padjadjaran, Indonesia

\begin{abstract}
The study aimed to carry out a semiotic analysis on a text of an English song lyric, which was limited airtime by the West Java Branch of the Indonesian Broadcasting Commission due to sexual content. The elements of eroticism in the song lyric were analyzed by using Barthes' semiotic theory, particularly the concepts of denotation, connotation, and myth. The research employs a qualitative method with a descriptive technique. The study shows that the lyric tends to show the implicit sexual contents rather than the explicit ones. It suggests that the song lyric constructs the myth of eroticism, which is driven by sexual desire in a relationship, instead of constructing pornographic content, which is usually intended to exploit sexual activities. However, the Indonesian Broadcasting Commission apparently regard eroticism to be the same as pornography since they banned the daytime broadcast of the song. The present study is expected to provide insight into the different concept between eroticism and pornography and thus it can be used to determine whether an adult content is indeed violating the norms of Indonesian society or not.

Keywords-eroticism, myth, pornography, semiotics, song lyrics.
\end{abstract}

\section{INTRODUCTION}

Discussing eroticism cannot be separated from what a society believes to be the norms and ideology. Basically, eroticis $m$ is believed as the reflective concept of western cultures (Fellmann, 2016). The erotic concept is also associated with psychological issues that depend on sexuality because it relates to internal factors of the human body such as neural system, internal stimuli, hormones that lead to stimulation. However, the perspective of the concept has been turned into a sexual activity of humans outside its primary objective to produce offspring and build human welfare. According to Morrow (2013), the term eroticism has been seen as the problematic issue because the meaning linguistically has shifted into prostitution, pornography, and obscenity. It means that the meaning is discursive from its original purposes that violate the social values of human.

In Indonesia, eroticism that contains sexual sensation is considered as a part of pornography and the content is regulated by the law. There are some signs that can stimulate sexual sensation such as facial expressions, gestures, postures, sounds, sentences, objects, aromas, touches, and combinations (Naibaho, 2014). The Republic of Indonesian law number 44 article 1 (2008) defines pornography as "images, sketches, illustrations, photos, writings, sounds, moving images, animations, cartoons, conversations, gestures, or other forms of messages through various forms of communication media or performances in public which contain obscenity or exploitation sexual violation of moral norms in society". It means that the Indonesia government really concerns with this issue in order to realize a society that adheres to moral ethics, religious values, and human dignity. Besides, the impact of the issue may occur especially to the morality of Indonesian young generation. According to Fagan (2009), sexual contents can increase the stress that can lead to negative attitudes toward the willingness of sexual activity.

Nowadays, the spreading of erotic contents is unavoidable. There are a lot of available media that can be used to exploit it either in visual or non-visual forms. The convenience of accessing online media is also one of the factors that make it difficult to maintain. Eroticism is not only explored through the visual images, bodies, or illustrations but also it is explicitly or implicitly conveyed through words. The media that potentially contains eroticism is music especially the lyrics. Song lyrics principally contain messages created to express feelings, conditions, experiences, etc. Additionally, lyrics may reflect the social life, culture, and ideology of the creators that are delivered explicitly or implicitly. Lyrics, however, do not always contain positive contents, which can be consumed by people of all ages. They also sometimes explicitly or implicitly include negative contents, which are only appropriate for particular ages. In this case, the important thing to investigate further is whether eroticism and pornography have the same meaning and function? 
The West Java Branch of Indonesian Broadcasting Commission has recently limited the schedule for screening and airing seventeen foreign language songs to be played in the West Java region. The song lyrics are considered to include sexual contents such as sexual activity and obscenity that can give negative influence, especially for children. Moreover, most of the lyrics are assumed to exploit women as an object of sexuality. The limitation is applied because they regard it to violate the regulation of Indonesian Broadcasting Commission that concerns with broadcast program standard. The regulation says that the broadcast program is prohibited from containing songs or videos that display lyrics containing sex, obscenity, and impressing sexual activity. This is actually the second regulation implemented by the government to limit airtime of such song. The first regulation was implemented in 2015 to limit some songs in Dangdut genre, a genre of Indonesian folk and traditional popular music, which are believed to include erotic contents. In this case, society is not fully aware of the meaning of the lyrics because the content that involves eroticism is sometimes delivered implicitly. Some of them may consider it as natural, but the others may see it as something that is inappropriate particularly for children and teenagers (Naibaho, 2014). Furthermore, this regulation is tightly related to sexual harassment happened in Indonesia especially in West Java. Besides, erotic contents, which are mostly reflecting the western culture, in a song lyric are potentially adopted by teenagers that lead them to a free-sex lifestyle. This action is thought to violate the social and religious norms of Indonesia.

Lyrics are communicated through language. Danesi (2004) states that Saussure defines language as a system of signs that function to express ideas. Furthermore, signs can be everything as long as it has meaning. Signs may in the forms of visual, verbal, and non-verbal objects. A song lyric is a part of a verbal sign because it is associated with words that imply meaning. In regard to this is sue, the primary objective of this study is to analyze the concept of eroticism in a text of song lyrics that have become an issue in West Java through a semiotic approach proposed by Barthes (1957). The present writers also study the myth constructed by the lyrics through the analysis of semiological chain, which consists of denotation and connotation, and structuralism, particularly from syntagmatic and paradigmatic relations.

The word semiotics, which is derived from the Greek word semion, refers to sign or seme as sign interpreter. Semiotics is one of the linguistic fields focusing on the study of signs as a part of communication. A sign can mean everything. It means that everything that has meaning is regarded as a sign. Saussure uses the term semiology to refer to semiotics. Semiology is an approach that studies signs in social life. Danesi (2004) states that Saussure proposed the dichotomy concept of sign, called as signifier and signified, which cannot be separated from each other. Furthermore, Saussure defines a sign as the arbitrary relationship between signifier and signified, which is called as signification. Besides, the concept of dichotomy is also seen as the differentiation between langue and parole, synchrony and diachrony, and syntagm and paradigm. This term of semiology is continued by the French linguist Roland Barthes (1952-1980). According to Allen (2003), Barthes admits that he was the first linguist who was influenced by the Swiss linguist Ferdinand de Saussure. Furthermore, he developed Saussure's concept of semiotics and proposed the theory of myth known as Mythology. Barthes used the term signifier as expression (E) and the signified as content (C). Thus, the signification here is the relation (R) between the expression (E) and its content (C) that produces meanings (Barthes, 1977). $\mathrm{R}$ also has a function to create and differentiate meanings.

Barthes divides two levels of meaning system, the first-order meaning and second-order meaning (Allen, 2003). In the first-order meaning, it is the general meaning that is accepted by the convention of society. This level is studied by Saussure that includes a signifier, a signified and the combination in a sign. In addition, the first-order meaning is regarded as denotative meaning. Then, the second-order meaning is the creation of a particular meaning or an extensional meaning. This second order of the system creates a new meaning that is different from the first-order meaning and known as connotative meaning. According to Danesi \& Perron (1999), connotative meaning allows the signs to be extended based on the context. Moreover, Barthes (1957) states that the first-order meaning is the element which builds the myth in the second-order meaning. He also adds that myth has a function to transform, to distort, and to naturalize the meaning from the first-order system in order to create new meaning in the second-order system. Therefore, Barthes's theory of connotative meaning is used to analyze the data of this research in order to explore the connotative meaning as well as the myth constructed by the song lyrics.

The topic of the research is rarely studied. Some researchers who studied eroticism used a different perspective. Naibaho (2014), for example, studied eroticism in Dangdut music of Indonesia and the result showed that most of the lyrics used words and phrases 
containing eroticism. The other research is from Ramadhani (2018) who found that most of the Indonesian songs tend to contain more implicit words in stating eroticism and vulgarity. In relation to the previous studies, the present research applies a different perspective to examine eroticism. It uses a semiotic approach proposed by Barthes. In addition, the study uses a different data resource, i.e. English language songs.

\section{METHODS}

The present study uses qualitative research. Creswell (2012) stated that qualitative research is a good way to address a research problem in which you do not know the variables and need to explore. In addition, According to Saldana (2011), qualitative research is an umbrella term for a wide variety of approaches to and methods for natural social life. The qualitative research concerns the nature of the reality of the data, social relationship between the researcher and the object of the research. In this case, qualitative research is used to explore eroticism concept in a song lyric and to interpret it based on the culture existing in society. To support the result, an interview is employed. Nine informants were chosen for the interview consisting of adults and teenagers. In addition to that, the informants were chosen because they are familiar with the song.

The data were collected based on the seventeen English songs that Indonesian Broadcasting Commission banned daytime broadcast in the region of West Java. Basically, the data was chosen because of the pros and cons regarding this issue and the study is intended to demonstrate whether the song lyrics contain the concept of eroticism or pornography and in what ways the concept violates the social values or the ideology of Indonesian society. The song that we analyzed is from Zayn Malik entitled Dust till dawn. It was chosen because of the grade of music trending in some of the media broadcasters in West Java. This song was so popular at that time and most of the teenagers consumed it. The grade of a song is determined by the frequency of people in listening to it, which indicates the number of people who request the song to be played. There are some steps in conducting this research. First, the lyric was classified to determine which parts of the song that potentially contained eroticism or pornography. Second, the parts of the song lyric were analyzed through the system of meaning, consisting of denotation and connotation, as well as the dichotomy concept of syntagmatic and paradigmatic relations. Afterwards, the interview was employed in order to gain perspective from society toward the song that was assumed to violate the law or social value. Last, the results were broadly discussed to find out what concept was constructed by the lyric and to explore how the ideology of society influenced the regulation.

\section{RESULTS AND DISCUSSION}

According to Hoed (2011), eroticism is derived from the ancient Greek word, eros which is 'the name of the god of love, the son of Aphrodite' and eroticism is defined as sexual excitement. The concept is associated with the arousal of sexual desire that is based on libido. Meanwhile, the word libido itself, according to a dictionary of Indonesian KBBI (2016), is defined as the human's lust that relates to an instinct. Therefore, eroticism is basically connected to 'love' in the aspect of the libido that is based on the relationship between a man and a woman. This also means that eroticism can be categorized as a theme, a nuance, and a condition related to or based on love, lust, and romance in order to arouse sexual desire between a man and a woman without considering as obscenity or violence. On the other hand, pornography has a different meaning from eroticism. According to Hoed (2011), pornography is also derived from the ancient Greek word, porne meaning 'prostitute' and graphein, which refers to 'write or writing'. In addition, pornography has a basic meaning as 'obscene', 'scurrilous', and 'rude'. It suggests that pornography is considered as explicit sexual writings, images, videos, sounds, or other materials aimed to cause sexual arousal, lurid, or sensational material, which are often displayed in combination, such as violence pornography. There are some particular characteristics that are explicitly categorized as pornography such as materials that contain a discursive sexual activity, sexual harassment, masturbation, nudity, and displaying sex organ. From the definition above, it clearly shows that eroticism refers to attitude, condition, and situation that are based on libido, which generally denotes sexual desire. Unlike eroticism, pornography tends to show sexual acts in order to arouse human's lust and the way it is served tends to show obscurity. Although eroticism and pornography have similar contact on sexuality, eroticism tends to show sexual desire, which is based on human's instinct rather than sexual acts that are based on obscurity and rudeness. The description of the concepts is important to discuss here because it is used as the basis to analyze the lyric of Zayn Malik's song in relation to eroticism and pornography.

Zayn Malik's song, entitled Dust till dawn, was released on the seventh of September 2017. The genre of the song is categorized as a love song because the lyric contains romanticism. The song is also considered having 
a deep meaning because it tells his relationship with a girl who is really close to him. Through this song, he wants to show his feelings to the girl that he loves. This song was so phenomenal because it achieved more than seven million viewers a day just after the song was released. However, the song becomes an issue in Indonesia particularly in West Java because of the sexual content. To know either the lyrics contain eroticism or pornography, Roland Barthes's semiotic theory is employed for data analyses.

\subsection{Data 1 'I wanna touch you'}

Based on syntagmatic relation, the relation between $I$, wanna (the non-standard form from want to), touch, and you clearly adheres to the English structure, consisting of subject, verb, and object and each of the words also has a particular meaning. The pronoun $I$ refers to the man, who is singing the song. The verbs wanna and touch function as the verb of the clause, while the pronoun you serves as the object of the clause. It means that the sequence of words in the clause has a certain function, which makes up a particular meaning. If the sequence is changed, for example, into you touch I wanna, the syntagmatic relation of the clause changes. As a result, it has no meaning because it does not follow the structure of English. Paradigmatically, the pronoun $I$ and you are the words which refer to someone or human and it can be changed by particular words such as man, woman, Zayn, Malik, Ahmad, etc. Then, the word want that is a verb has an associative relationship with the words need, demand, require, desire or wish for, meaning these words can replace the word want as the verb of the clause. Then, the word touch associatively relates to the words feel, stroke, make contact with, or fondle. This as sociative relations hip is known as the paradigmatic association, which appears with the component outside of the structure. The word touch is used to relate to physical action comparing to its other associative words, which provide a particular meaning. It indicates that if the words are changed with their associative words, they will influence the meaning of the clause. The analysis in general shows that the lyric I wanna touch you is a sign that has a structural relation in terms of syntagm and paradigm and thus it has meaning.

Based on Barthes' system of meaning, denotation and connotation, the word $I$ is a signifier referring to the person who speaks, which in this context is the man singing the lyric. Then, the signifier wanna has a mental concept that relates to a wish for a particular thing, the word touch means to be so close together without space between, and the signifier you refers to the interlocutor. If the signifiers are seen as a whole in the denotative level, it means an expression showing a desire to be so close together. In the second-order meaning (connotation), the clause I wanna touch you signifies a different meaning, i.e. man's sexual desire in a relationship.

\subsection{Data 2 'I wanna feel you'}

The clause I wanna feel you is regarded as a sign that has structure and meaning. This structure observes the sequence of English structure in which the subject $(I)$ is followed by a verb (wanna feel) and an object (you). This relation is known as syntagmatic relation. It means that the relation between I, wanna (the non-standard form from want to), feel, and you certainly follows the sequence of English structure and thus the string of words makes up meaning. The clause is categorized as a simple sentence where $I$ is the subject of the clause, which refers to the man and has a function to do an action in the clause. The words wanna feel which are the verb of the clause have a function to give an action to the subject. Then, the pronoun you in this clause is the object of the clause which position is after the verb. It shows that every word in the clause serves a function. If the position is changed into, for instance, I feel wanna you, it violates the English structure and causes the string of words meaningless. If this relation is seen as paradigmatic relation, the words $I$ and you, which refer to someone, can be replaced by particular words or such as man, woman or proper names such as Zayn, Malik, etc. Then, the word want, which is the verb of the clause has an associative relation with the words need, demand, require, desire or wish for, which mean that those words can replace the word want. The word feel also can be replaced by the words experience, touch, finger, or fondle that have as sociative relations.

Based on the first-order meaning (denotation) and the second-order meaning (connotation), the clause is analyzed to identify its initial meaning by using signifier and signified relationship. The word $I$ as the signifier of the first-order meaning refers to the person who speaks and the signifier you is the person that is addressed. Meanwhile, the word wanna refers to a wish of a particular thing and it may also refer to a plan of action. The other signifier, the word feel, has the initial meaning that is to experience something physical or emotional. If this clause is interpreted in the first-order meaning, it means an expression showing a wish to experience someone either physically or emotionally. Based on the second-order meaning, which is an extensional meaning on the basis of social perspective, the string of words signifies man's sexual desire in a relationship that is driven by libido.

\subsection{Data 3 'I wanna see the sunrise and your sins'}


The group of words in I wanna see the sunrise and your sins is a simple sentence because it consists of one subject and one verb. The position of I, wanna, see, the sunrise and your sins follows the sequence of the English structure and thus it has meaning. The pronoun $I$ is the subject of the sentence, which refers to someone doing the action. The words wanna to see functions as the verb, which does the action to the subject. The phrase the sunrise and your sins is the object of the clause. From this explanation, it indicates that every word in the clause serves a different function that creates a certain meaning. If the sequence is altered, for example, it changes into wanna the sunrise and your sins see I, it will violate the English structure. As a result, the group of words does not create meaning. It suggests that the meaning of the clause depends on the structure. Paradigmatically, each of the words in the sentence can be replaced by other words that are in line with the structure of an English sentence. For example, the pronoun $I$ that refers to someone can be replaced by other words such as man, woman, Zayn, Malik, Ahmad, etc.

Based on Barthes' system of meaning, denotation and connotation, the sentence I wanna see the sunrise and your sins is analyzed from the relationship between signifier and signified. In the first-order meaning, the word $I$ is the signifier referring to the person who is speaking; the signifier wanna means a wish of a particular thing or a plan of action; the signifier see means to be conscious of what is around us by using our eyes; sunrise and sins refer to the time in the morning when the sun starts to rise in the sky and the breaking of moral value. If this clause is denotatively seen as the whole unit of meaning, it signifies a wish to wake up together in the morning after performing an act considered as a sin. In the second-order of meaning, connotation, the group of words signifies an activity driven by sexual desire that is done by a couple at night and the moment they wake up in the morning they find themselves still together.

\subsection{Data 4 'let's make love tonight'}

The clause let's make love tonight in the lyrics also has the structure that makes up meaning. In syntagmatic relation, this clause is considered as an imperative sentence because of the omission of the subject. Besides, the meaning of the clause indicates an invitation to someone signified by the verb let's. The words let, us, make, love, and tonight is arranged based on the sequence of English structure to create a certain meaning. The word let's in the sentence, which means persuasion, is usually placed in the initial sentence in English that is always followed by another verb (make). The words love is the object while tonight is the adverb of the clause. It indicates that each word has a particular function in the clause and creates meaning. Paradigmatically, the words also have a vertical relationship, meaning each word can be replaced by other words that have associative meanings. The word make, for example, can be replaced by the words produce, create, perform, or do while the word love can be replaced by passion, affection, warmth, or intimacy. It means that these words, which are outside of the structure can be used to replace its associative word, but they will bring different meanings. For instance, if the lyric is changed into let's create love tonight, it constitutes a different meaning because the combination of make and love creates a particular meaning.

Based on Barthes' system of meaning, the clause let's make love tonight is analyzed from denotation and connotation. The signifier let's means persuasion; make refers to producing something by using particular materials; and love means sexual attraction or having a great interest in something very much. The sign let's make love tonight in the first-order meaning suggests an invitation to produce love. In the second-order meaning, however, it signifies a different meaning, i.e. an expression to invite someone to do sexual activity driven by sexual desire due to love relationship.

Based on the lyrics that have been analyzed through Barthes' system of meaning, it can be seen that the verbal signs in the song lyrics signify the concept of eroticism, reflecting sexual desire rather than sexual acts. The words do not explicitly display the obscurity and rudeness such as nudity, vital organs, sexual actions, that are categorized as pornography. The sign such as the expression make love in the lyric refers to a man's sexual desire to a woman without displaying any concept of obscurity. To support the interpretation, the present writers consider people's perspective by doing an interview with some teenagers and adults about the song. It is found that that most of them who listened to the song do not totally focus on the meaning of the lyrics. Most of them argued that the musical tone of the song is the thing that they were attracted to. Additionally, they in general do not really understand the implicit meaning of the song. In spite of that, they actually familiar with the meaning of make love. However, they felt that sexual activity denoted by English words, such as make love, is not as vulgar as Indonesian words. Therefore, they often used English expressions as mitigators.

The next interesting question to discuss is why eroticism in the lyrics of Zayn Malik's song matters in Indonesia especially in West Java region so that the West Java Branch of Indonesian Broadcast Commission is sued 
a regulation to limit airtime of the song. To explore the question, the myth constructed in the song lyrics needs to examine further. When most of the participants especially teenagers hear the words making love, they consider it having negative sense, even some adults regard it a taboo. Basically, 'making love' and 'having sex' have a different meaning. "Making love' refers to the stages of love between couples who love each other, and are committed legally. Unlike making love, "having sex" tends to be more negative because it refers to sexual activity without commitment and official ties, such as free sex or onenight dating. However, many people cannot differentiate and consider them as taboo. This is apparently the myth constructed by the people in West Java that leads to an ideology that is based on the social norms and religion.

The other factor that may arise this issue is the identity of Indonesia that is known as a religious country. Beside the norms and the laws that need to be followed, the Indonesian people also cannot be separated from their religion. It means that social life strongly adheres to religious norms. It can be seen from Pancasila, which is a fundamental constitution of the country, whereby the Sila one says Ketuhanan Yang Maha Esa 'belief in the one and only God'. It means that every regulation created by the government cannot be separated from religious norms. Furthermore, Indonesia is well known as the biggest follower of Islam in the world. The data showed that, especially in West Java, more than $80 \%$ of the people are Muslim. Historically, West Java was regarded as the central arrival of the spread of Islam in Indonesia. The establishment of this country also cannot be separated from the influence of Islam. One of the Islamic teachings to maintain the social life is the prohibition of sexual activity without marital status. Although Indonesia is not an Is lamic country, most of the social actions and cultures strongly relate to the role of religion. In addition, culture is also considered to influence this regulation. The Province of West Java which people are mostly Sundanese and Muslim highly upholds etiquette in social action. It suggests that religious norms and cultures have a crucial role to regulate social life.

In western countries such as America, the lifestyle that society mostly embraces is secularism. Secularism is an ideology in which a state of the institution must stand apart from religion. It means most of the social action in western countries does not strongly adhere to religious norms. For instance, they tend to regard sexual activity without marital status as something natural. Therefore, eroticism found in the lyrics of the song created and sung by western singers is expressed freely. In Indonesia especially West Java, the sexual content in the song lyrics became an issue because it is considered to violate not only the religious norms but also the norm in Sundanese culture. It is thought to be in line with the social ethic that highly upholds by society. It strongly suggests that the song was limited airtime not only because of the laws, which are regulated by the government, but also the religious norms and culture. The implementation of this regulation also aimed to prevent sexual harassment and free-sex activities among teenagers. However, the analysis above indicates that sexual contents in the song lyrics tend to construct the concept of eroticism, which is regarded as something natural in a relationship because human basically have a desire, rather than pornography, which is usually intended to arouse desire and exploit sexual activities.

\section{CONCLUSION}

Based on the analysis, it is found that the lyric of Zayn Malik's song, entitled Dust till Dawn, constructs the myth of eroticism that is driven by sexual desire in a relationship. The lyric implicitly indicates sexual activity and thus it reflects the concept of eroticism rather than pornography. There are some words indicating sexual desire done by a man and a woman, i.e. 'touch the body', 'feel the body', and 'make love'. The words do not explicitly display obscurity, but signify how a man shows his sexual desire to his lover. Most people in Indonesia, particularly in West Java, apparently believe that the words 'making love' have negative sense, strongly associated with sexual activity rather than the stages of love between couples that love each other and commit legally. In addition, the words are different from 'having sex', which are more negative in terms of meaning. This signification is driven by an ideology constructed from social and religious norms. Therefore, it is not surprising if the Indonesian Broadcasting Commission regarded eroticism to be the same as pornography and finally banned the daytime broadcast of the song. The present study is expected to provide insight into the different concept between eroticism and pornography studied from the semiotic analysis. Furthermore, the signification of eroticism this study may be used to consider whether an adult content is indeed violating the norms of Indonesian society or not.

\section{REFERENCES}

[1] Allen, G. (2003). Roland Barthes. USA and Canada: Routledge.

[2] Barthes, R. (1957). Mythologies. Paris: Editions du Seuil.

[3] Barthes, R. (1977). Image music text. London: Fontana Press.

[4] Creswell, J. W. (2012). Educational research. Pearson. 
[5] Danesi, M. (2004). Messages, signs, and meaning: a basic textbook in semiotics and communication theory (3rd edition). Toronto: Canadian Scholars' Press Inc.

[6] Danesi, M., \& Perron, P. (1999). Analyzing cultures. USA: Indiana University Press.

[7] Fagan, P. (2009). The Effects of Pornography on Individuals, Marriage, Family and Community | MARRI Research. Retrieved May 5, 2019, from https://marri.us/research/research-papers/the-effects-ofpornography-on-individuals-marriage-family-andcommunity/

[8] Fellmann, F. (2016). Eroticism: why it still matters. The Creative Commons Attribution International License.

[9] Hoed, B. H. (2011). Semiotik \& dinamika sosial budaya. Depok: Komunitas Bambu.

[10] Kementerian Pendidikan dan Kebudayaan Republik Indonesia. (2016). Kamus Besar Bahasa Indonesia.

[11] Morrow, R. (2013). Sex Research and Sex Therapy: A Sociological Analysis of Masters and Johnson. Routledge.

[12] Naibaho, S. B. (2014). Erotisme dalam lirik lagu dangdut Indonesia.

[13] Ramadhani, A. R. (2018, July). The Depiction of Erotism In Spanish and Indonesian Song Lyrics. Presented at the International Conference on Language Phenomena in Multimodal Communication (KLUA 2018). https://doi.org/10.2991/klua-18.2018.54

[14] Saldana, J. (2011). Fundamentals of Qualitative Research. Oxford, New York: Oxford University Press. 